\title{
ASSIMILATION PATTERNS IN THE USE OF ADVANCED MANUFACTURING TECHNOLOGIES IN SMES: EXPLORING THEIR EFFECTS ON PRODUCT INNOVATION PERFORMANCE
}

\author{
Sylvestre Uwizeyemungu \\ Université du Québec à Trois-Rivières, Trois-Rivières, Canada \\ Placide Poba-Nzaou \\ Université du Québec à Montréal, Montréal, Canada \\ Josée St-Pierre \\ Université du Québec à Trois-Rivières, Trois-Rivières, Canada
}

\begin{abstract}
Manufacturing small and medium-sized enterprises (SMEs) are more and more adopting advanced manufacturing technologies (AMT) aimed at fostering product innovation process, improving product quality, streamlining the production process, and gaining productivity. In this study, we analyze the relationship between AMT proficiency levels in manufacturing SMEs and product innovation performance. Using data from 616 manufacturing SMEs, and considering a wide range of various AMT (20 different types of AMT grouped into 5 categories), we derived three AMT assimilation patterns through a cluster analysis procedure combining hierarchical and non-hierarchical clustering algorithms. The analysis of the relationship between AMT assimilation patterns and product innovation performance shows a rather unexpected picture: in spite of the existence of clearly distinct patterns of AMT assimilation, we find no significant relationship between any pattern and product innovation performance. Instead, we find the organizational and environmental context of SMEs to be more determinant for product innovation performance than any of the AMT assimilation patterns. From a practical point of view, this study indicates that manufacturing SMEs managers interested in fostering their innovation capabilities through AMT assimilation need to be aware of the contingency effects of their organizational size, age, and sector of activity.
\end{abstract}

Keywords: Advanced manufacturing technology, information technology, product innovation, performance, small to medium-sized enterprise, SME.

\section{INTRODUCTION}

The need to meet the requirements of demanding customers and keep up with tough competition puts pressure on manufacturing small and medium-sized enterprises

\footnotetext{
Manuscript first received/Recebido em: 20/12/2014 Manuscript accepted/Aprovado em: 15/05/2015

Address for correspondence / Endereço para correspondência

Sylvestre Uwizeyemungu, Université du Québec à Trois-Rivières, 351 Boulevard des Forges, TroisRivières, QC G9A 5H7, Canadá Canada, E-mail: sylvestre.uwizeyemungu@uqtr.ca

Placide Poba-Nzaou, Université du Québec à Montréal, Canada, E-mail: poba-nzaou.placide@uqam.ca Josée St-Pierre, Université du Québec à Trois-Rivières, Canada, E-mail: josee.st-pierre@uqtr.ca
} 
(SMEs) to offer high-quality and innovative products while being efficient in their production processes. The intensity of this pressure is such that SMEs have to simultaneously excel in various areas, without making trade-offs (Lagacé \& Bourgault, 2003). The implementation of information technologies (IT), particularly advanced manufacturing technologies (AMT), has been seen as an important step forwards for SMEs in their quest to achieve a wide range of organizational and technological benefits (Thomas, Barton, \& John, 2008) such as innovation and productivity that help them deal with the market pressure they experience.

However, it has been argued that the effective implementation of quality improvement approaches or tools (including AMT) in SMEs is hindered by these firms' limited resources and knowledge (Desai, 2008; Thomas, Barton, \& Chuke-Okafor, 2009). Hence the need to account for the specificities of SMEs when analyzing the contribution of AMT to organizational performance (Raymond \& St-Pierre, 2005; Thomas et al., 2008). One cannot simply assume that the types of AMT that are advantageous in the context of large enterprises (LE), the underlying models of adoption and exploitation, and the results achieved would be necessarily transposable as such to SMEs. Differences between LEs and SMEs with regards to resource constraints, organizational contingencies, as well as entrepreneurial and strategic choices are likely to play a determinant role when it comes to antecedents and outcomes of AMT implementations.

Manufacturing SMEs, given their constraints, particularly in terms of resources and expertise, cannot always invest in a wide range of AMT. They need to decide carefully among the multiple AMT available to which they will dedicate their limited resources. Which AMT does it matter for manufacturing SMEs to highly assimilate? More precisely, for which types of AMT do SMEs need to develop high levels of proficiency in order to reach higher performance levels in terms of product innovation? Are there any particular AMT assimilation patterns that could be associated with product innovation performance?

We explore these questions through an analysis of data collected from a sample of 616 manufacturing SMEs. We derived three AMT assimilation patterns (three clusters) through a cluster analysis procedure combining hierarchical and nonhierarchical clustering algorithms. In spite of clearly distinct patterns of AMT assimilation, we find no significant relationship between any patterns and related product innovation performance. Instead, we find that the organizational and environmental contexts of SMEs are more determinant for product innovation performance than any of the AMT categories.

The remainder of this paper is organized as follows: in section 2 we present the research's theoretical and empirical background leading to our research model. We set forth our research methodology in section 3. We reveal the results of our analysis in section 4 and we analyze and discuss them in section 5. It is also in this last section that we discuss the theoretical and practical implications of our results, the research limitations, and the research avenues.

\section{THEORETICAL AND EMPIRICAL BACKGROUND}

2.1. Advanced Manufacturing Technologies: Definition and Classification 
The various technologies grouped under the label AMT and broadly defined by OECD as "computer-controlled or micro-electronics-based equipment used in the design, manufacture or handling of a product" (Thomas \& Barton, 2012, p. 747) are diversely classified in literature. For instance Spanos and Voudouris (2009) distinguished (1) stand-alone, (2) intermediate, and (3) integrated technologies whereas Raymond and Croteau (2006) proposed a three-category typology of advanced manufacturing systems (AMS): (1) product design technologies (AMS for innovation), (2) process technologies (AMS for flexibility), and (3) logistics/planning applications (AMS for integration). This last categorization is particularly interesting as it implies the objectives pursued by adopting organizations. In this study, we adopt this last classification with a slight variation. We split the last category of logistics/planning applications (IT for integration) into two parts, by removing transactional and logistic applications and grouping them under the label of AMT for logistic and monitoring, while keeping the remaining applications under the label of AMT for integration. In Table 1 we present the four categories of AMT that are used in the present study.

\subsection{AMT in SMEs}

\subsubsection{AMT Adoption Challenges in SMEs}

SMEs aiming at adopting AMT are confronted with challenges related to their internal and external environments. With regards to internal environment, the lack of resources impedes even the appropriate assessment of the benefits SMEs could reap from the implementation of AMT (Koc \& Bozdag, 2009; Thomas \& Barton, 2012). Indeed, the selection of a number of AMT to be implemented in a firm is part of a process towards a targeted model for an organizational design that managers think is compatible with external market requirements (Cardoso, Pinheiro de Lima, \& Gouvea da Costa, 2012). AMT are thus resources meant to achieve specific manufacturing capabilities (internal requirements) that would allow the adopting firms to achieve improved operational and strategic results. This difficulty is part of a broader set of problems faced by SMEs in their quest to adopt and exploit AMT. In general, most SMEs lack what Sohal et al. (2006) refer to as "assets for AMT", that is the resources necessary for properly developing and using AMT. In other words, SMEs are not only deterred by the extensive capital investment necessary to adopt and implement AMT, but they also lack technical and manufacturing infrastructure to support these technologies (Thomas \& Barton, 2012). In this sense, the notion of "assets for AMT" is close to the concept of absorptive capacity (Spanos \& Voudouris, 2009).

Beyond resources, there are also other internal factors that play a determinant role in the adoption of AMT in SMEs. For example, the characteristics of the entrepreneur (education level, experience in industry) and the entrepreneurial strategic orientation (development on new markets, adoption on new technologies) have been found to influence the nature of AMT adopted in SMEs (Raymond \& St-Pierre, 2005). Interestingly, it also appears that the nature of operational performance achieved with the initial AMT adopted by SMEs has a crucial role with regard to additional investments in AMT: improvements in quality and flexibility induce firms to adopt further AMT, while achievements in terms of low-cost, innovation, and delivery capability do not lead to further AMT adoption (Spanos \& Voudouris, 2009).

The levels of adoption of AMT are also influenced by the external environment of SMEs (e.g. customers and vendors) (Lefebvre, Lefebvre, \& Harvey, 1996; Spanos \& Voudouris, 2009). SMEs exposed to some types of AMT through their relationship with their customers or suppliers will likely tend to adopt the same technologies. The type of 
production (sector of activity) and the commercial dependency have also been identified by Raymond and St-Pierre (2005) as other environmental factors that can influence SMEs with respect to AMT adoption.

Table 1: Classification of Advanced Manufacturing Technologies (AMT)

Product Design Technologies (AMT for Innovation):

- Computer-aided design and manufacturing (CAD/CAM)

- Computer-aided design (CAD)

- Computer-aided drawing

- Computer-aided manufacturing (CAM)

Process Technologies (AMT for Flexibility):

- Flexible manufacturing systems (FMS)

- Programmable logic controller (PLC)

- Automated handling of materials

- Computer numerically controlled machines (CNC)

- Robotized operations

Transactional and Logistic Applications (AMT for logistic and monitoring):

- Bar codes

- Production inspection \& control

- Computer-based production scheduling

- Computer-aided maintenance

- Quality control system

- Computer-based inventory management

Communication and Integration Applications Systems (AMT for Integration):

- Enterprise resource planning (ERP)

- Material requirement planning (MRP-I)

- Manufacturing resource planning (MRP-II)

- Electronic data interchange (EDI)

- LAN for MRP-II/Plant/Intranet

\subsubsection{State of AMT Adoption in SMEs}

It is not easy to get from the literature on the subject a more or less complete picture of the state of AMT adoption in SMEs. Studies do not use the same list of technologies, which makes it difficult to compare their results. However, in spite of this limitation, a consistent conclusion stems from previous studies: SMEs, generally undercapitalized and resource-constrained (Franquesa \& Brandyberry, 2009), tend to adopt only a few types of AMT. Koc et al. (2009) identified three main types of AMT common in SMEs: LAN (Local Area Network), CAD, and CAM. Automated storage, robotics, and WAN 
(Wide Area Network) were found to be the less commonly diffused in sampled SMEs. According to the authors, the adoption of LAN was a response to a need by the SMEs to integrate all their functions under a computer network in order to achieve better performance outcomes. As for the adoption of CAD and CAM, it is consistent with the nature of the job shop processes in SMEs, characterized by a high degree of customization. CAD and CAM would allow SMEs to meet the design challenges stemming from the differentiation requirements of their markets. In another study, Raymond (2005) identified computer-based inventory management, computer-aided drawing (CAD), and equipment controlled by programmable automata as the most prevalent AMT of the study's sampled SMEs. In the same study, flexible manufacturing systems (FMS), and MRP-II were the least common. The results of this study show that no category of AMT among the four categories we defined earlier (cf. Table 1) is predominantly adopted by SMEs. They rather reflect a "pick and choose" strategy (Lagacé \& Bourgault, 2003, p. 706) amongst different categories of AMT.

\subsection{AMT and Firm Performance}

Prior studies examining the performance effects of AMT adoption and usage have produced conflicting results (Bülbül, Ömürbek, Paksoy, \& Bektas, 2013; Koc \& Bozdag, 2009). While some reported positive results, others reported negative results. For example, when comparing two samples of firms from Sweden and Singapore, Zhou et al. (2009) found that AMT investments were correlated with firm performance in Sweden, but not in Singapore. In a longitudinal study based on data collected from 308 companies over 22 years, Birdi et al. (2008) did not find a statistically significant relationship, direct or indirect, between AMT and productivity. Overall, failures in AMT projects are more common than successes, and the situation appears to be more dramatic in SMEs (Koc \& Bozdag, 2009).

The analysis of the research results that report positive impacts of AMT shows that the AMT - performance relationship is complex. Some studies have established that the AMT-performance relationship is either mediated (Choe, 2004; Patterson, West, \& Wall, 2004) or moderated (Laosirihongthong \& Himanghsu, 2004; Lewis \& Boyer, 2002; Zhang, Vonderembse, \& Cao, 2006) by other factors such as: operation improvement practices, quality management practices, workers' empowerment, etc. The requirement of complementary resources is another facet of the complexity of AMT performance relationship. In accordance with the resource-based theory, complementary resources or investments are generally necessary and sometimes indispensable for organizations to take advantage of their AMT investments. Investing in training and mentoring (Fulton \& Hon, 2010), as well as in developing close buyer-supplier relationships (Rahman \& Bennett, 2009; Rahman, Brookes, \& Bennett, 2009) improves the likelihood of better AMT performances. It would also be beneficial to invest in organizational structure adaptation: the low levels of productivity gained from AMT even several years after their implementation in Indian manufacturing firms are attributed to the incompatibility of new technologies with the organizational structure that has not evolved (it was and remained mechanistic) (Ghani, Jayabalan, \& Sugumar, 2002). In other studies (Lewis \& Boyer, 2002; Small, 2007) it has been found that the business value of AMT investments is conditional to the implementation efforts and to the deployment of the appropriate implementation strategies.

The above considerations highlight the importance of appropriateness of AMT with regards to the organizational context; which leads to the concept of "fit" or "alignment". In accordance with the contingency theory perspective, the effects of AMT 
on organizational performance would stem from their fit or alignment with other organizational dimensions. For example, it has been found that the "fit" (conceptualized as profile deviation) between process environment and AMT leads to superior performance, and the "mismatch", which is the deviation from ideal profiles, has a negative impact on manufacturing performance (Das \& Narasimhan, 2001). In other studies, the alignment between strategies and different types of AMT (Kotha \& Swamidass, 2000), and the alignment of SMEs' network, product and market development with their levels of AMT integration and assimilation (Raymond \& Croteau, 2006) were associated with better performance.

The availability of several types of AMT means that companies can combine them in various ways. Hence the importance of identifying AMT investment patterns and their respective impact on performance outcomes. Diaz et al (2003) identified three groups corresponding to different patterns of AMT investment behavior (groups labelled traditionalists, designers, and investors). However, they were unable to relate different performance levels to the identified groups. Later on, in other studies, differences in performance results were related to different AMT investment patterns (Bülbül et al., 2013; Chung \& Swink, 2009).

\subsection{Research Model}

In this study, we analyze the patterns of AMT assimilation in SMEs, as well as their corresponding performance in terms of product innovation. Our research model (Figure 1 ) is based on the assumption that firms choose among diverse available types of AMT a set of technologies more or less assorted. They then implement those technologies with great or less success in terms of assimilation (or proficiency in use). We postulate that it is the level of assimilation of the various adopted AMT that determines the level of product innovation achieved.

\section{Figure 1: Research Model}

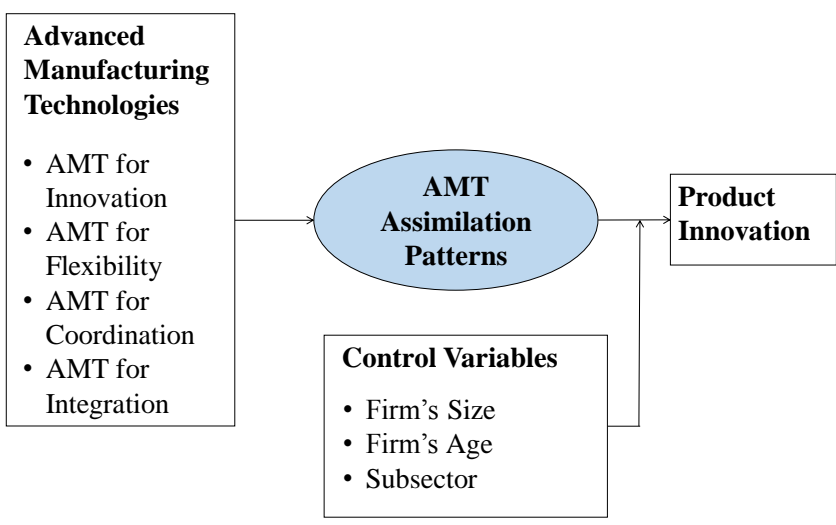

As the implementation of AMT occur in a context that can moderate their effects on organizational performance, our research model takes into account some contextual variables, namely the firm's size and age, and its subsector of activity. Previous studies have established that the firm's size (Gupta \& Whitehouse, 2001; Laforet, 2013; Tambe \& Hitt, 2012), the firm's age (Balasubramanian \& Lee, 2008; Withers, Drnevich, \& Marino, 2011), and the nature of activity (Dangayach \& Deshmukh, 2005; Raymond, Bergeron, \& Croteau, 2013) have an impact on the adoption of technological innovations and on the latter's effects on performance outcomes. 


\section{RESEARCH METHOD}

\subsection{Data Source}

For the purpose of this study we used data previously collected from manufacturing SMEs by a university research center. In cooperation with an important business association, this center has created a database that contains information on a wide range of business practices and on various aspects of these SMEs' organizational performance. SME owner-managers and key employees filled out a questionnaire and provided their firm's financial statements for the last three years. On the basis of the information supplied, a comparative diagnosis (benchmarking) of their firm is provided to owner-managers, assessing the firm's overall situation in terms of performance and vulnerability. These diagnoses link the SMEs' results to their organizational resources and business practices (including advanced manufacturing technologies), and formulate recommendations as to what actions should be undertaken in short and medium terms to improve performance and/or reduce vulnerability.

\subsection{Sample}

For this study's purposes we retrieved from the database data on 673 manufacturing firms, and we retained 616 observations after removing cases with under 10 employees (42 cases) or over 250 employees (15 cases). The upper limit of 250 employees corresponds to the OECD definition of SMEs based on size. Manufacturing firms under 10 employees were excluded as being too small with limited likelihood of interest in AMT. The analysis of missing values in our data set (using the SPSS Missing Values Analysis - MVA - algorithm) shows that missing values represent 840 of the 13,944 values (cases $\mathrm{x}$ variables), that is $5.68 \%$. This rate falls in the range of 5 to $15 \%$, which implies that the handling of missing values requires sophisticated methods (Acuña \& Rodriguez, 2004). Considering this result, we decided to estimate missing values even if the Little's MCAR test succeeded ( $p$-value of $0.463>0.05$ ). We estimated missing values using multiple imputation technique as recommended in such a situation (Acock, 2005; Potthoff, Tudor, Pieper, \& Hasselblad, 2006; Schafer \& Graham, 2002).

The mean number of employees of the 616 manufacturing SMEs included in our sample is 54 employees (standard deviation: 45), and the median is 40 employees. The mean age of SMEs in our sample is 38.6 years (s.d.: 23.3), with a median of 33 years.

The manufacturing SMEs studied are spread over 20 sub-sectors. The most represented sub-sectors include metal products $(37.7 \%)$, rubber and plastic industry $(12.7 \%)$, wood industry $(9.1 \%)$, electrical and electronic products $(6.5 \%)$, machinery $(6.2 \%)$, and food products and beverages $(5.8 \%)$. When grouped according to the OECD's four-category classification of industrial sectors based on the technological intensity (OECD, 2005) SMEs in our sample are divided into the following proportions: there are 166 (26.9\%) low-tech SMEs, 351 (57.0\%) medium to low-tech SMEs, 99 $(16.1 \%)$ medium to high-tech SMEs. There are no SMEs in high-tech category. Finally, it is worth mentioning that although our sample consists mainly of Canadian firms (433 - 70.3\%), it also includes French (172 - 27.9\%) and Mexican companies (12 - 1.8\%). 


\subsection{Measurement}

Measures used for all of our variables (clustering variables, organizational performance variables, and control variables) are presented in Table 2.

\subsection{Cluster Analysis}

As previously stated, we used, as clustering variables, the levels of assimilation of various advanced manufacturing technologies (AMT) adopted by SMEs. We preferred levels of assimilation measured on an ordinal scale over a dichotomous measure of AMT adoption (0/1) as we anticipated, following previous studies (Raymond, 2005; Raymond \& Croteau, 2009), that assimilation matters more than mere adoption.

Table 2: Variables Measurement

\begin{tabular}{|c|c|c|c|}
\hline Category & Variable & Measure & References \\
\hline $\begin{array}{l}\text { Clustering } \\
\text { Variables }\end{array}$ & $\begin{array}{l}\text { Assimilation } \\
\text { levels of } 20 \\
\text { different AMT } \\
\text { adopted }\end{array}$ & $\begin{array}{l}\text { Proficiency in use of each AMT, on a scale of } 1 \\
\text { (low) to } 5 \text { (high). Whenever a given AMT is not } \\
\text { present, the proficiency score is } 0 .\end{array}$ & $\begin{array}{l}\text { Brandyberry et al. } \\
\text { (1999); Raymond } \\
\text { and Croteau (2009). }\end{array}$ \\
\hline $\begin{array}{l}\text { Organizational } \\
\text { Performance } \\
\text { Variable }\end{array}$ & Innovation & $\begin{array}{l}\text { Average percentage of sales attributed to new or } \\
\text { modified products over the last two financial } \\
\text { years. }\end{array}$ & $\begin{array}{l}\text { Becheikh et al. } \\
\text { (2006); Garcia et al. } \\
(2002) \text {. }\end{array}$ \\
\hline \multirow[t]{3}{*}{$\begin{array}{l}\text { Control } \\
\text { Variables }\end{array}$} & - Firm size & $\begin{array}{l}\text { Average number of employees over the two last } \\
\text { periods. }\end{array}$ & - \\
\hline & - Firm age & $\begin{array}{l}\text { Years of existence from the year of creation up to } \\
2014 \text { (2014-year of creation). }\end{array}$ & - \\
\hline & - Sub-sector & $\begin{array}{l}\text { OECD classification of industrial activities based } \\
\text { on technological intensity: low-tech (1), medium } \\
\text { to low-tech (2), medium to high-tech (3), and } \\
\text { high-tech (4). }\end{array}$ & OECD (2005). \\
\hline
\end{tabular}

Following Balijepally et al. (2011)'s recommendation, we combined two clustering methods: we first used the hierarchical clustering algorithm (agglomerative method) to decide upon the "optimal" number of clusters and determine the clusters centroids, and we then used these results as initial seeds for a non-hierarchical algorithm. To determine the "optimal" number of clusters, we applied the agglomerative hierarchical clustering algorithm (Ward's method) on our complete sample, and based upon the analysis on the dendrogram produced, we identified four plausible solutions, a 2-cluster solution, a 3-cluster solution, a 4-cluster solution, and an 8-cluster solution.

For determining among those solutions the one that would be stable, we randomly selected a first sub-sample of approximately $50 \%$ of our sample, and then a second sub-sample composed of approximately $30 \%$ of the full sample (using SPSS random selection procedure), and we applied the same clustering algorithm. The 
analysis of the dendrograms produced with the two sub-samples data indicated that the 3 -cluster solution was the most stable.

In the second phase of our cluster analysis, we applied the K-Means clustering algorithm, using $\mathrm{K}=3$, and the mean values produced in the 3 -solution cluster as initial seeds for the algorithm. Although the iteration number was tentatively set at 100 , the clustering results were convergent after 11 iterations.

\section{RESULTS}

\subsection{State of AMT Use in SMEs}

The four most prevalent AMT in the sampled SMEs are, in descending order: production inspection and control system (67.2\%), computer-based inventory management (66.6), computer-aided drawing (64.1\%), and quality control system (61.9\%). It is worth noting that three out of four AMT that are present in more than $60 \%$ of SMEs are in the category of AMT for logistic and monitoring. The least prevalent AMT are MRP-II (17.9\%), FMS (18.7), automated handling of materials (20.0\%), and computer-based maintenance management $(20.1 \%)$. AMT for integration registered the lowest rates of adoption in the sampled SMEs, closely followed by AMT for flexibility. The components of AMT for integration category are adopted by less than $30 \%$ of SMEs, except for ERP (41.4\%).

\subsection{Results of Cluster Analysis}

We present in Table 3 the final results of the earlier described clustering process. Our 616 SMEs are divided into three clusters, 170 (27.6\%) in cluster I, 162 (26.3\%) in cluster II, and $284(46.1 \%)$ in cluster III. Overall, SMEs in cluster I display the strongest AMT assimilation: they come first in three categories out of four, and second in the remaining category (AMT for logistic and monitoring). The lowest AMT assimilation levels are displayed by SMEs in cluster III: they come in the second position only in the category of AMT for innovation, and they come in the last position in the other three categories. SMEs in the cluster II fall globally in the middle position: they are, however, the strongest in the category of AMT for logistic and monitoring, and the weakest in the category of AMT for Innovation, and they come in the second position for the remaining categories.

The pair-wise differences between means on Tamhane's T2 post-hoc test (cf. subscripts following the means in Table 3) allow us to identify significant differences between the means of different clusters. Being in the middle position, cluster II offers a good starting point for a pair-wise comparison. The scrutiny of the results of Tamhane's T2 post-hoc test shows that the big difference between cluster II and cluster I lies in their respective levels of assimilation of mainly AMT for innovation, and secondarily AMT for flexibility, and AMT for logistic and monitoring. Their differences in terms of assimilation of AMT for integration are quite minimal: in this case, the sole component that is statistically distinctive when clusters I and II are compared is LAN for MRPII/Plant/Intranet.

The comparison between cluster II and III shows a quite different situation: the two clusters are significantly different on almost all AMT. Actually, there is only one AMT on a total of 20 on which the two groups are not significantly distant one from the other: they are statistically similar on their assimilation levels of only computer-aided manufacturing (CAM). Not surprisingly, cluster I and cluster III are far apart on the whole range of AMT. 
Table 3: AMT Assimilation Patterns Resulting from the Cluster Analysis

\begin{tabular}{|c|c|c|c|c|}
\hline \multirow[b]{2}{*}{ Clustering Variables } & \multicolumn{3}{|c|}{ Clusters } & \multirow[b]{2}{*}{$\begin{array}{c}\text { Anova } \\
\text { F }\end{array}$} \\
\hline & $\begin{array}{c}\mathrm{I} \\
(\mathrm{n}=170) \\
\text { Mean }\end{array}$ & $\begin{array}{c}\text { II } \\
(\mathrm{n}=162) \\
\text { Mean }\end{array}$ & $\begin{array}{c}\text { III } \\
(\mathrm{n}=284) \\
\text { Mean }\end{array}$ & \\
\hline AMT for Innovation & High & Low & Medium & \\
\hline $\begin{array}{l}\text { - Computer-Aided Design and Manufacturing } \\
\text { (CAD/CAM) }\end{array}$ & $2.49_{a}$ & $0.15_{\mathrm{c}}$ & $0.36_{b}$ & $194.7 * * *$ \\
\hline - Computer-Aided Design (CAD) & $3.53_{\mathrm{a}}$ & $0.54_{c}$ & $1.38_{\mathrm{b}}$ & $140.6 * * *$ \\
\hline - Computer-Aided Drawing & $4.07 \mathrm{a}$ & $1.47_{\mathrm{c}}$ & $2.18_{\mathrm{b}}$ & $97.9 * * *$ \\
\hline - Computer-Aided Manufacturing (CAM) & $3.39_{\mathrm{a}}$ & $0.41_{b}$ & $0.58_{\mathrm{b}}$ & $274.9 * * *$ \\
\hline AMT for Flexibility & High & Medium & Low & \\
\hline - Flexible Manufacturing Systems (FMS) & $0.97 \mathrm{a}$ & $0.57_{\mathrm{b}}$ & $0.27 \mathrm{c}$ & $17.4 * * *$ \\
\hline - Programmable Logic Controller (PLC) & $2.17_{\mathrm{a}}$ & $2.78_{\mathrm{b}}$ & $0.59_{\mathrm{c}}$ & $92.1 * * *$ \\
\hline - Automated Handling of Materials & $0.98_{\mathrm{a}}$ & $1.35_{\mathrm{a}}$ & $0.17_{\mathrm{b}}$ & $39.5^{* * *}$ \\
\hline - Computer Numerical Control (CNC) & $3.56_{\mathrm{a}}$ & $1.38_{\mathrm{b}}$ & $0.85_{\mathrm{c}}$ & $138.3^{* * *}$ \\
\hline - Robotics & $1.49_{\mathrm{a}}$ & $1.47 \mathrm{a}$ & $0.30_{\mathrm{b}}$ & $45.7 * * *$ \\
\hline AMT for Logistic and Monitoring & Medium & High & Low & \\
\hline - Bar Codes & $1.56_{\mathrm{a}}$ & $1.60_{\mathrm{a}}$ & $0.40_{\mathrm{b}}$ & $40.5^{* * *}$ \\
\hline - Production Inspection \& Control & $2.74_{b}$ & $3.40_{\mathrm{a}}$ & $1.54_{\mathrm{c}}$ & $70.4 * * *$ \\
\hline - Production Scheduling & $2.17_{\mathrm{a}}$ & $1.83_{\mathrm{a}}$ & $0.56_{\mathrm{b}}$ & $63.1 * * *$ \\
\hline - Computer-Aided Maintenance & $0.97 \mathrm{a}$ & $0.56_{b}$ & $0.15_{\mathrm{c}}$ & $32.3 * * *$ \\
\hline - Quality Control System & $2.89_{\mathrm{b}}$ & $3.33_{\mathrm{a}}$ & $1.18_{\mathrm{c}}$ & $105.1 * * *$ \\
\hline - Inventory Management System & $2.76_{\mathrm{b}}$ & $3.23_{\mathrm{a}}$ & $1.29 \mathrm{c}$ & $87.2^{* * *}$ \\
\hline AMT for Integration & High & Medium & Low & \\
\hline - $\quad$ ERP & $1.12_{\mathrm{a}}$ & $1.26_{\mathrm{a}}$ & $0.53_{\mathrm{b}}$ & $20.3^{* * *}$ \\
\hline - MRP-I & $1.45_{\mathrm{a}}$ & $1.10_{\mathrm{a}}$ & $0.34_{b}$ & $35.8^{* * *}$ \\
\hline - MRP-II & $0.85_{\mathrm{a}}$ & $0.51_{\mathrm{a}}$ & $0.12_{\mathrm{b}}$ & $27.2^{* * *}$ \\
\hline - EDI & $1.30_{\mathrm{a}}$ & $1.48_{\mathrm{a}}$ & $0.33_{\mathrm{b}}$ & $37.6^{* * *}$ \\
\hline - LAN for MRP-II/Plant/ Intranet & $1.40_{\mathrm{a}}$ & $0.87_{\mathrm{b}}$ & $0.26_{c}$ & $42.2 * * *$ \\
\hline
\end{tabular}

$\mathrm{a}, \mathrm{b}, \mathrm{c}$ : Within rows, different subscripts indicate significant $(\mathrm{p}<0.05)$ pair-wise differences between means on Tamhane's T2 (post hoc) test

In Tables 4 and 5, we present the breakdown of control and organizational performance variables by AMT assimilation patterns. Table 5 shows the results for the sub-sector, and Table 4 shows the results for the rest of the control and organizational performance variables. These results allow us to analyze differences between the three clusters with regard to variables "theoretically related to the clusters, but not used in defining clusters" (Ketchen Jr. \& Shook, 1996, p. 447). Here again, the results of the Tamhane's T2 post-hoc test help us establish pair-wise differences.

With regard to the firm's size, clusters I and II are statistically comparable, even though SMEs in cluster I are relatively larger than SMEs in cluster II (mean size of 
respectively 71 and 60 employees). SMEs in cluster III are the smallest (40 employees on average), and significantly different from SMEs in the other two clusters. Regarding the age of firms, clusters I and II, with the mean age of 41.8 and 40 years respectively, are comparable and above the mean age of the entire sample (38.6 years). SMEs in cluster III, with the mean age of 35.6 years, are younger than SMEs in clusters I and II. The difference between clusters with respect to age is statistically significant only between cluster I and III.

Table 4: Breakdown of Control and Organizational Performance Variables by AMT Assimilation Patterns

\begin{tabular}{|c|c|c|c|c|c|}
\hline & \multicolumn{3}{|c|}{ Cluster } & \multirow[b]{2}{*}{ Total } & \multirow[b]{2}{*}{ Anova } \\
\hline & I & II & III & & \\
\hline & $(n=170)$ & $(\mathrm{n}=162)$ & $(n=284)$ & $(n=616)$ & \\
\hline Variables & Mean & Mean & Mean & Mean & $\mathbf{F}$ \\
\hline \multicolumn{6}{|c|}{ Control Variables } \\
\hline - $\quad$ Firm's size & $70.93_{\mathrm{a}}$ & $60.05_{a}$ & $39.91_{b}$ & 53.76 & $29.9 * * *$ \\
\hline - Firm's age & $41.87 \mathrm{a}$ & $40.03_{\mathrm{a}, \mathrm{b}}$ & $35.89_{b}$ & 38.63 & $4.0^{*}$ \\
\hline \multicolumn{6}{|c|}{ Performance Variable } \\
\hline - Innovation & 0.12 & 0.12 & 0.10 & 0.11 & 1.7 \\
\hline
\end{tabular}

$*: \mathrm{p}<0.05 ; * * *: \mathrm{p}<0.001$ (2-tailed tests)

$\mathrm{a}, \mathrm{b}, \mathrm{c}$ : Within rows, different subscripts indicate significant $(\mathrm{p}<0.05)$ pair-wise differences between means on Tamhane's T2 (post hoc) test.

Table 5: Breakdown of Sub-Sectors by AMT Assimilation Patterns

\begin{tabular}{|c|c|c|c|c|c|c|c|c|c|}
\hline \multirow[b]{3}{*}{ Sub-Sector } & \multicolumn{7}{|c|}{ Cluster } & & \multirow{3}{*}{$\chi^{2}$} \\
\hline & \multicolumn{2}{|r|}{ I } & \multicolumn{2}{|r|}{ II } & \multicolumn{2}{|c|}{ III } & \multicolumn{2}{|c|}{ Total } & \\
\hline & $\mathrm{f}$ & $\%$ & $f$ & $\%$ & $\mathrm{f}$ & $\%$ & $f$ & $\%$ & \\
\hline - Low-Tech & 24 & 3.9 & 55 & 8.9 & 87 & 14.1 & 166 & 26.9 & \\
\hline $\begin{array}{l}\text { - Medium to Low- } \\
\text { Tech }\end{array}$ & 127 & 20.6 & 89 & 14.5 & 135 & 21.9 & 351 & 57.0 & $39.58 * * *$ \\
\hline $\begin{array}{l}\text { - Medium to High- } \\
\text { Tech }\end{array}$ & 19 & 3.1 & 18 & 2.9 & 62 & 10.1 & 99 & 16.1 & \\
\hline Total & 170 & 27.6 & 162 & 26.3 & 284 & 46.1 & 616 & 100 & \\
\hline
\end{tabular}

The breakdown of sub-sectors by AMT assimilation patterns presented in Table 5 shows that the different sub-sectors are not randomly distributed into the three clusters 
(global chi-square of $39.58, \mathrm{p}<0.001$ ). To further clarify this conclusion, we present in Table 6 what expected percentages of each sub-sector in the three clusters would be if the distribution were random. These expected percentages take into account the actual distributions of SMEs in different sub-sectors and in different clusters. The comparison of percentages in Tables 5 and 6 shows that low-tech SMEs are under-represented in the cluster I (and inversely over-represented in the clusters II and III) while medium to lowtech SMEs are over-represented in the cluster I (and inversely under-represented in the clusters II and III). Medium to high-tech firms are over-represented in the cluster III (and inversely under-represented in the clusters I and II).

Table 6: Expected Distribution (\%) of SMEs Pertaining to Different Subsectors in Different Clusters under the Hypothesis of Random Distribution

\begin{tabular}{llrrr}
\hline & & \multicolumn{3}{c}{ Cluster (\%) } \\
\cline { 2 - 4 } Sub-Sector (\%) & I (27.6) & II (26.3) & III (46.1) \\
\hline • Low-Tech (26.9) & 7.4 & 7.1 & 12.4 \\
- Medium to Low-Tech (57.0) & 15.7 & 15.0 & 26.3 \\
- & Medium to High-Tech (16.1) & 4.4 & 4.2 & 7.4 \\
\hline
\end{tabular}

With regard to product innovation performance, the ANOVA results (Table 4) show that there are no significant differences between clusters. These results are further discussed in section 5 .

\section{DISCUSSION OF THE RESULTS}

\subsection{Analysis of the Results}

Do the results indicate that advanced manufacturing technologies (AMT) play a determinant role in fostering product innovation performance? The cluster analysis clearly shows that there are three distinct AMT assimilation patterns amongst the sampled SMEs, but the relationship between these patterns and product innovation performance seems to be elusive.

As apparent in Table 4, SMEs in cluster III tend to be smaller (mean size of 40 employees) than SMEs in other clusters (60 employees in cluster I, and 71 employees in cluster II). However, the difference between clusters I and II in terms of size is not statistically significant. As small firms experience a greater impact from their adoption of innovations (including technologies) (Laforet, 2013), they would need lower proficiency levels to achieve good results in terms of product innovation. Their small size allows them to be more reactive to changes in their environment than bigger enterprises would be. In addition, the proximity of smaller firms to their market is another factor conducive to their being innovative and effective. This situation compensates for their weak mastery of AMT.

Firms in cluster I are the oldest (mean age of 41.9 years), although the age variance between them and firms in cluster II (40 years) is not statistically significant. The age variance between these two clusters (I and II) and cluster III (35.9) is significant, and this difference may explain why firms in cluster III perform relatively well: they achieve comparable results with firms in the other two clusters in spite of their being less proficient in terms of AMT. As innovation propensity is higher in 
younger firms than in older ones (Huergo \& Jaumandreu, 2004), younger firms in cluster III may achieve good innovation results even with their lower levels of proficiency with AMT. The results of this study seem to confirm the observation that the forces of organizational inertia that increases as firms get older prevail over the benefits of organizational learning gained with time (Balasubramanian \& Lee, 2008). However, our conclusion in this respect is to be taken with caution given that the "benefits of organizational learning" are limited to product innovation in our study.

Another possible factor that explains the results as far as product innovation is concerned would be related to environmental uncertainty. Organizations operating in a highly uncertain environment are likely to be compelled to innovate at a higher rate than organizations in a less uncertain environment. We do not have a measure of environmental uncertainty in our research variables, but the industrial sector (measured through technological intensity) can be used as a proxy for such a measure. The overrepresentation of SMEs in the category of medium to high-tech sub-sector (the highest technology-intensive sector in our sample) in the cluster III would explain the relatively good performance of this group on product innovation performances. However, this explanation is weakened by the observation that the predominance of low-tech SMEs in cluster II does not prevent them from achieving comparable results as the other groups in terms of product innovation.

Instead of considering the overall AMT assimilation levels, one could try to analyze the assimilation levels by AMT category, and see if some subtle effects of each category on product innovation performance would be found. As SMEs in cluster I display the highest levels of assimilation of AMT for innovation, one would expect them to perform better on innovation performance, at least when compared to SMEs in cluster II which display the lowest assimilation levels in the same category. The actual results show that the expected relationships do not necessarily materialize. The fact that SMEs with the highest assimilation levels in AMT for innovation (cluster I) do not show outstanding innovation performance, as it was expected, could be explained by the negative moderating effect of AMT for integration, category in which the same SMEs display the highest assimilation levels. Indeed, it has been noted that high levels of information technology (IT) integration tend to negatively affect the market-oriented flexibility of the production process (Brandyberry et al., 1999) and to disable SMEs' innovation capability effects on productivity (Raymond et al., 2013).

\subsection{Implications, Limitations, and Research Avenues}

Theoretical and practical implications can be drawn from this study. The first theoretical contribution of this study is to make relative the cause and effect relationship between advanced manufacturing technologies (AMT) and product innovation performance, at least in the context of small and medium-sized enterprises (SMEs). Notably, the results from this study show that for product innovation in SMEs the organizational and environmental context is more determinant than the actual levels of AMT assimilation.

As our second theoretical contribution, we have used the measures of AMT assimilation as independent variables instead of the more usual IT adoption. When using AMT adoption as independent variables, firms are split into two categories, the adopters and non-adopters. The assimilation measure allows us to fine-tune the analysis, as one passes from a 0-1 scale to a 0-5 scale, allowing for the application of a form of gradation among firms that have adopted the technology but display varying degrees of proficiency in the use of that technology. 
The third contribution of this study stems from the spectrum of the AMT covered. Twenty different AMT grouped into four categories are included in this study. Taking into consideration multiple AMT allows for the considerations of the potential synergistic and conflicting effects of different technologies. It also allows for the analysis of the effectiveness of various resource configurations (or resource patterns). As AMT are available from vendors, any firm, provided that it has access to necessary resources, can choose any among them. Therefore, the AMT-related competitive advantage does not reside into the technologies themselves, but in their ingenious combination; a combination that would be hard for competitors to imitate. This is consistent with the resource-based view (RBV), a theoretical framework that is widely used to explain the impact of IT on organizational performance (Bhatt \& Grover, 2005; Uwizeyemungu \& Raymond, 2012).

From a practical point of view, this study elucidates the fact that manufacturing SMEs managers interested in fostering their innovation capabilities through AMT assimilation need to be aware of the determinant role of their organizational and environmental contexts. When deciding for which types of AMT they will allocate their limited resources, they should take into account the contingency effects of their organizational size, age, and sector of activity. For instance, owner-managers and manufacturing plants managers in SMEs, in particular older SMEs, should be aware of the damaging effects of organizational inertia phenomena. This study suggests that this phenomena could, in the long run, lead to the erosion of benefits due to the implementation and exploitation of AMT. SMEs' managers will have to find ways to thwart such erosion. For AMT vendors and consultants, this study signals a need for them to develop a differentiating scale of offers for SMEs with regard to the various organizational and environmental contexts.

The first limitation of this study relates to the AMT assimilation measures that are based on self-reported ratings from operations and manufacturing managers. These subjective measures may lead to bias given that different individuals may diversely judge the levels of proficiency.

Another limitation is not having considered whether SMEs are subcontractors or not, while this status may influence the production systems and the type of innovation adopted. In future research, the mediating role of this status may be taken into consideration.

As organizational performance indicator, we have used product innovation. Even though product innovation is a good indicator of manufacturing SMEs' performance, one could choose other performance indicators such as product and process quality, productivity, profitability, sales revenue, growth, etc. AMT effects may vary according to the business performance indicators one considers. This consideration applies also to the control variables. For instance, it would have been interesting to have data on environment uncertainty, and analyze its effects on the relationship between AMT assimilation patterns and organizational performance. In the same way, it would be interesting to analyze the mediating role of networks in which SMEs are involved. As a research avenue, future research could analyze the AMT assimilation patterns on other performance measures, and include other control variables. Additionally, future research could focus on the efforts to identify the effective combinations of different AMT in SMEs. The results of this kind of research will allow SMEs to wisely spend their limited resources on AMT that best provide for the achieving of the desired performances. 


\section{References}

Acock, A. C. (2005). Working With Missing Values. Journal of Marriage and Family, 67(4), 1012-1028.

Acuña, E., \& Rodriguez, C. (2004). The Treatment of Missing Values and its Effect in the Classifier Accuracy. In D. Banks, L. House, F. R. McMorris, P. Arabie \& W. Gaul (Eds.), Classification, Clustering and Data Mining Applications (pp. 639-648). BerlinHeidelberg: Springer-Verlag.

Balasubramanian, N., \& Lee, J. (2008). Firm Age and Innovation. Industrial and Corporate Change, 17(5), 1019-1047.

Balijepally, V., Mangalaraj, G., \& Iyengar, K. (2011). Are We Wielding this Hammer Correctly? A Reflective Review of the Application of Cluster Analysis in Information Systems Research. Journal of the Association for Information Systems, 12(5), 375-413.

Becheikh, N., Landry, R., \& Amara, N. (2006). Lessons from Innovation Empirical Studies in the Manufacturing Sector: A Systematic Review of the Literature from 19932003. Technovation, 26(5/6), 644-664.

Bhatt, G. D., \& Grover, V. (2005). Types of Information Technology Capabilities and their Role in Competitive Advantage: An Empirical Study. Journal of Management Information Systems, 22(2), 253-277.

Birdi, K., Clegg, C., Patterson, M., Robinson, A., Stride, C. B., Wall, T. D., \& Wood, S. J. (2008). The Impact of Human Resource and Operational Management Practices on Company Productivity: A Longitudinal Study. Personnel Psychology, 61(3), 467-501.

Brandyberry, A., Rai, A., \& White, G. P. (1999). Intermediate Performance Impacts of Advanced Manufacturing Technology Systems: An Empirical Investigation. Decision Sciences, 30(4), 993-1020.

Bülbül, H., Ömürbek, N., Paksoy, T., \& Bektas, T. (2013). An Empirical Investigation of Advanced Manufacturing Technology Investment Patterns: Evidence from a Developing Country. Journal of Engineering and Technology Management, 30(2), 136156.

Cardoso, R. D. R., Pinheiro de Lima, E., \& Gouvea da Costa, S. E. (2012). Identifying Organizational Requirements for the Implementation of Advanced Manufacturing Technologies (AMT). Journal of Manufacturing Systems, 31(3), 367-378.

Choe, J.-M. (2004). Impact of Management Accounting Information and AMT on Organizational Performance. Journal of Information Technology, 19(3), 203-214.

Chung, W., \& Swink, M. (2009). Patterns of Advanced Manufacturing Technology Utilization and Manufacturing Capabilities. Production and Operations Management, 18(5), 533-545.

Dangayach, G. S., \& Deshmukh, S. G. (2005). Advanced manufacturing technology implementation: Evidence from Indian small and medium enterprises (SMEs). Journal of Manufacturing Technology Management, 16(5/6), 483-496.

Das, A., \& Narasimhan, R. (2001). Process-Technology Fit and its Implications for Manufacturing Performance. Journal of Operations Management, 19(5), 521-540. 
Desai, D. A. (2008). Cost of Quality in Small- and Medium-Sized Enterprises: Case of an Indian Engineering Company. Production Planning \& Control, 19(1), 25-34.

Diaz, M. S., Machuca, J. A. D., \& Alvarez-Gil, M. J. (2003). A view of Developing Patterns of Investment in AMT through Empirical Taxonomies: New Evidence. Journal of Operations Management, 21(5), 577-606.

Franquesa, J., \& Brandyberry, A. (2009). Organizational Slack and Information Technology Innovation Adoption in SMEs. International Journal of E-Business Research, 5(1), 25-48.

Fulton, M., \& Hon, B. (2010). Managing Advanced Manufacturing Technology (AMT) Implementation in Manufacturing SMEs. International Journal of Productivity and Performance Management, 59(4), 351-371.

Garcia, R., \& Calantone, R. (2002). A Critical Look at Technological Innovation Typology and Innovativeness Terminology: A Literature Review. Journal of Product Innovation Management, 19(2), 110-132.

Ghani, K. A., Jayabalan, V., \& Sugumar, M. (2002). Impact of Advanced Manufacturing Technology on Organizational Structure. Journal of High Technology Management Research, 13(2), 157-175.

Gresov, C., \& Drazin, R. (1997). Equifinality: Functional Equivalence in Organization Design. Academy of Management Journal, 22(2), 403-428.

Gupta, A., \& Whitehouse, F. R. (2001). Firms Using Advanced Manufacturing Technology Management: An Empirical Analysis Based on Size. Integrated Manufacturing Systems, 12(5), 346-350.

Huergo, E., \& Jaumandreu, J. (2004). How Does Probability of Innovation Change with Firm Age? Small Business Economics, 22(3/4), 193-207.

Ketchen Jr., D. J., \& Shook, C. L. (1996). The Application of Cluster Analysis in Strategic Management Research: An Analysis and Critique. Strategic Management Journal, 17(6), 441-458.

Koc, T., \& Bozdag, E. (2009). The Impact of AMT Practices on Firm Performance in Manufacturing SMEs. Robotics and Computer-Integrated Manufacturing, 25(2), 303313.

Kotha, S., \& Swamidass, P. M. (2000). Strategy, Advanced Manufacturing Technology and Performance: Empirical Evidence from U.S. Manufacturing Firms. Journal of Operations Management, 18(3), 257-277.

Laforet, S. (2013). Organizational Innovation Outcomes in SMEs: Effects of Age, Size, and Sector. Journal of World Business, 48(4), 490-502.

Lagacé, D., \& Bourgault, M. (2003). Linking Manufacturing Improvement Programs to the Competitive Priorities of Canadian SMEs. Technovation, 23(8), 705-715.

Laosirihongthong, T., \& Himanghsu, P. (2004). Competitive Manufacturing Strategy: An Application of Quality Management Practices to Advanced Manufacturing Technology Implementation. International Journal of Business Performance Management, 6(3,4), 262-286. 
Lefebvre, L. A., Lefebvre, E., \& Harvey, J. (1996). Intangible Assets as Determinants of Advanced Manufacturing Technology Adoption in SME's: Toward an Evolutionary Model. IEEE Transactions on Engineering Management, 43(3), 307-322.

Lewis, M. W., \& Boyer, K. K. (2002). Factors Impacting AMT Implementation: An Integrative and Controlled Study. Journal of Engineering and Technology Management, 19(2), 111-130.

OECD. (2005). Oslo Manual: Guidelines for Collecting and Interpreting Innovation Data (OECD Ed. 3 ed.). Paris: OECD.

Patterson, M. G., West, M. A., \& Wall, T. D. (2004). Integrated Manufacturing, Empowerment, and Company Performance. Journal of Organizational Behavior, 25(5), 641-665.

Payne, G. T. (2006). Examining Configurations and Firm Performance in a Suboptimal Equifinality Context. Organization Science, 17(6), 756-771.

Potthoff, R. F., Tudor, G. E., Pieper, K. S., \& Hasselblad, V. (2006). Can One Assess Whether Missing Data Are Missing at Random in Medical Studies? Statistical Methods in Medical Research, 15(3), 213-234.

Rahman, A. A., \& Bennett, D. (2009). Advanced Manufacturing Technology Adoption in Developing Countries. Journal of Manufacturing Technology Management, 20(8), 1099-1118.

Rahman, A. A., Brookes, N. J., \& Bennett, D. J. (2009). The Precursors and Impacts of BSR on AMT Acquisition and Implementation. IEEE Transactions on Engineering Management, 56(2), 285-297.

Raymond, L. (2005). Operations Management and Advanced Manufacturing Technologies in SMEs: A Contingency Approach. Journal of Manufacturing Technology Management, 16(7/8), 936-955.

Raymond, L., Bergeron, F., \& Croteau, A.-M. (2013). Innovation Capability and Performance Of Manufacturing SMEs: The Paradoxical Effect of IT Integration. Journal of Organizational Computing and Electronic Commerce, 23(3), 249-272.

Raymond, L., \& Croteau, A.-M. (2006). Enabling the Strategic Development of SMEs through Advanced Manufacturing Systems. Industrial Management \& Data Systems, 106(7), 1012-1032.

Raymond, L., \& Croteau, A.-M. (2009). Manufacturing Strategy and Business Strategy in Medium-Sized Enterprises: Performance Effects of Strategic Alignment. IEEE Transactions on Engineering Management, 56(2), 192-202.

Raymond, L., \& St-Pierre, J. (2005). Antecedents and Performance Outcomes of Advanced Manufacturing Systems Sophistication in SMEs. International Journal of Operations \& Production Management, 25(5/6), 514-533.

Schafer, J. L., \& Graham, J. W. (2002). Missing Data: Our View of the State of the Art. Psychological Methods, 7(2), 147-177.

Small, M. H. (2007). Planning, Justifying and Installing Advanced Manufacturing Technology: A Managerial Framework. Journal of Manufacturing Technology Management, 18(5), 513-537. 
Sohal, A. S., Sarros, J., Schroder, R., \& O'Neill, P. (2006). Adoption Framework for Advanced Manufacturing Technologies. International Journal of Production Research, 44(24), 5225-5246.

Spanos, Y. E., \& Voudouris, I. (2009). Antecedents and Trajectories of AMT Adoption: The Case of Greek Manufacturing SMEs. Research Policy, 38(1), 144-155.

Tambe, P., \& Hitt, L. M. (2012). The Productivity of Information Technology Investments: New Evidence from IT Labor Data. Information Systems Research, 23(3), 599-617.

Thomas, A. J., Barton, R., \& Chuke-Okafor, C. (2009). Applying Lean Six Sigma in a Small Engineering Company - A Model for Change. Journal of Manufacturing Technology Management, 20(1), 113-129.

Thomas, A. J., Barton, R., \& John, E. G. (2008). Advanced Manufacturing Technology Implementation. International Journal of Productivity and Performance Management, 57(2), 156-176.

Thomas, A. J., \& Barton, R. A. (2012). Characterizing SME Migration towards Advanced Manufacturing Technologies. Proceedings of the Institution of Mechanical Engineers, Part B: Journal of Engineering Manufacture, 226(4), 745-756.

Uwizeyemungu, S., \& Raymond, L. (2012). Impact of an ERP System's Capabilities upon the Realisation of its Business Value: A Resource-Based Perspective. Information Technology and Management, 13(2), 69-90.

Withers, M. C., Drnevich, P. L., \& Marino, L. (2011). Doing More with Less: The Disordinal Implications of Firm Age for Leveraging Capabilities for Innovation Activity. Journal of Small Business Management, 49(4), 515-536.

Zhang, Q., Vonderembse, M. A., \& Cao, M. (2006). Achieving Flexible Manufacturing Competence. International Journal of Operations \& Production Management, 26(6), 580-599.

Zhou, H., Leong, G. K., Jonsson, P., \& Sum, C.-C. (2009). A comparative Study of Advanced Manufacturing Technology and Manufacturing Infrastructure Investments in Singapore and Sweden. International Journal of Production Economics, 120(1), 42-53. 